EDITORIAL

\title{
Retos de la bioética frente a la biotecnología. Necesidad de la educación en bioética.
}

\author{
Pablo Arango Restrepo, MD, MSc, PhD.
}

Médico de la Universidad de Caldas, Especialista en Cirugía Ortopédica y Traumatología de la Universidad Javeriana. Docente del Departamento de Bioética y profesor investigador en el área de la bioética y ortopedia de la Universidad de la Sabana'.

1. El Dr. Pablo Arango se vinculó al departamento de ortopedia del Hospital de La Samaritana como médico especialista en 1982 y trabajó en este hospital 11 años y en los dos últimos fue el Director Científico del Hospital. Posteriormente, se vinculó a la Universidad de La Sabana donde diseńo la facultad de medicina y se desempeńó como su primer decano durante tres ańos, posteriormente fue Vicerrector Académico de la Universidad. En la actualidad ejerce la cirugía ortopédica y es profesor del

Departamento de Bioética y profesor investigador en el área de la bioética y la ortopedia. Fue uno de los fundadores de la revista Persona y Bioética hace 10 años. Obtuvo la Maestría en Bioética en la Universidad de Murcia, en Espańa y en el año 2009 el

Doctorado en Medicina en dicha Universidad. Ganó el Premio Internacional en Ciencias de la Salud Juan Jacobo Muńoz en el año 2004. Ha escrito múltiples artículos de ortopedia y de bioética en revistas nacionales y extranjeras.

"La humanidad posee hoy instrumentos de potencia inaudita. Puede hacer de este mundo un jardin o reducirlo a un cúmulo de escombros. Ha logrado una extraordinaria capacidad de intervenir en las fuentes mismas de la vida, o ceder al orgullo miope de una ciencia que no acepte límites, llegando incluso a pisotear el respeto debido a cada ser humano. Hoy, como nunca en el pasado, la humanidad está en una encrucijada»

Juan Pablo II, Homilía, 8.octubre. 2000

La bioética como disciplina surgió en la segunda mitad del siglo XX como fruto de la preocupación de muchos científicos y pensadores por el avance de la ciencia que amenazaba el futuro de la humanidad. Los avances biotecnológicos siguen apareciendo y pueden afectar seriamente la vida y la dignidad de los seres humanos. El cientificismo es una corriente de pensamiento que valora excesivamente los adelantos

científicos y maneja unos modelos bioéticos no conformes al respeto por los demás. Se plantea la necesidad de una educación bioética con unas premisas antropológicas respetuosas de la persona humana.

\section{Introducción}

Los desarrollos biotecnológicos son cada día noticia y la inmensa mayoría de ellos tienen alguna relación directa con la manipulación de la vida humana y por tanto de una manera u otra nos afecta. Desde el año 1971 Van Rensselaer Potter bioquímico y oncólogo norteamericano acuño el termino bioética (1) para referirse a la necesidad de disponer de una serie de principios éticos que protegiesen a la humanidad de los peligros de los avances científicos que si bien pueden hacer bien, también pueden convertirse en un peligro. El hombre perdió su inocencia con la explosión de las bombas atómicas en Hiroshima y Nagasaki, quedó demostrado que los adelantos científicos pueden volverse contra el mismo hombre ocasionando su autodestrucción.

En la actualidad no se habla de ética médica, se habla de bioética, que es un concepto más amplio dado que los problemas que se plantean hoy en día fruto de los enormes adelantos científicos son problemas complejos y en los que ya no sólo 
participan médicos sino profesionales de diversas disciplinas $(2,3)$ como la biología, la genética, la embriología, etc., y son problemas no limitados al ámbito de un consultorio sino que son de ámbito global e interdisciplinario.

Los desarrollos tecnológicos y científicos nos asombran cada día. La primera y segunda revolución industrial duraron un siglo, la tercera es la de las telecomunicaciones y la cuarta la biotecnológica que está en curso, y en ella la bioética tiene mucho que decir.

\section{Algunos adelantos científicos actuales que generan dificultades éticas}

Voy a referirme a 4 adelantos científicos que generan problemas bioéticos.

1. Proyecto genoma humano. El Proyecto genoma humano comenzó hace unos 20 años y pretende tener la secuencia de los genes humanos. En el año 2000 se presentó un informa preliminar con mucho bombo en los medios de comunicación, el entonces presidente Clinton dijo "Estamos aprendiendo el lenguaje utilizado por Dios para crear la vida", un periodista decía "El hombre llegó a este planeta sin un libro de instrucciones pero desde hoy este libro existe: está con nosotros haciendo buen uso de él". Y otro dijo "El genoma tendrá un profundo impacto en nuestras vidas y en las de nuestros hijos, revolucionará el diagnóstico, la prevención y el tratamiento de gran parte, si no de todas las enfermedades humanas. Para nuestros nietos el cáncer podría ser sólo un signo del zodíaco". Estas frases indudablemente tienen un carácter muy periodístico y no son precisas. El genoma humano nos ha permitido conocer algo de la estructura de nuestro organismo, pero no sabemos cómo funcionan todos esos millones de elementos químicos y bioquímicos que lo integran.

Sabemos que muchas enfermedades tienen una base genética pero no se pueden afirmar que sea una sola la causa, podríamos decir que los genes si nos dan una estructura que nos predispone a ciertas enfermedades, pero para que estas ocurran tiene que concurrir muchos otros factores de índole ambiental, alimenticio, de comportamientos, preventivo, etc. Conocer las predisposiciones de una persona a una enfermedad puede ayudar a prevenirla y esto es importante. Una aplicación práctica actual es que la genética ayuda a determinar, en determinados casos, si a un enfermo con cáncer o con una infección, o que requiere estar anti coagulado que medicamento es más efectivo (4). Esto es lo que se conoce como la medicina personalizada, que promete medicamentos y terapias más precisas y especificas para el enfermo $(5,6)$.

La información genética de la persona en manos de terceros hace que un aspecto de la intimidad de las personas se pierda, todos tenemos derecho a mantener nuestra intimidad. "La intimidad es mucha más que aquello que se tiene en reserva. Es el espacio en que se esconde lo más vulnerable de nuestra condición humana porque allí se guarda con sigilo lo más secreto y preciado de nuestro ser. De ahí que sea preciso exponerlo tan sólo en circunstancias que nos garanticen que se tratará con la mayor consideración" dice Ángela Marulanda. Para muchos el derecho a la intimidad es un derecho humano muy importante que se atropella a diario en los hospitales y que requiere un estudio muy cuidadoso $(7,8)$.

Los datos del genoma de una persona en manos inescrupulosas puede generar una discriminación por parte de empleadores, de compañías de seguros o de compañías de salud. Si una compañía de seguros sabe que determinado cliente tiene una propensión a determinadas enfermedades puede negarse a venderle un seguro de vida, o una compañía de salud puede decidir que a un individuo con ciertas predisposición a una enfermedad no le vende el seguro o no le excluye determinados tratamientos. También pueden presentarse problemas en el campo laboral y ocurrir que a una persona que solicite un empleo y se lo nieguen porque se puede prever que va a estar enfermo y a tener incapacidades laborales.

Es un error pensar que la información que nos da el genoma es algo absoluto, que estamos realmente determinados por nuestros genes (9). Este error de concepto ha llevado a mujeres adolescentes que son portadoras del gen conocido como el BRCA1 y BRCA2, que predispone al cáncer de seno en un pequeńo porcentaje de casos, a pedir se les practique una mastectomía (10). La genética 
juega un papel en la presencia de enfermedades, pero no es absoluto, hay niños gemelos y uno sufre de diabetes y otro no, la genética es un elemento dentro más dentro de las variadas causas de una enfermedad, las costumbres alimenticias, los aspectos climáticos y ambientales, los hábitos saludables, otras enfermedades concomitantes, las medidas preventivas, los chequeos médicos, etc. Pensar que es sólo la genética es caer en un determinismo genético, que es una actitud equivocada.

2. La clonación. Es un procedimiento que aplicado en el campo de los alimentos vegetales y animales puede ser muy beneficioso para la humanidad. Ha permitido multiplicar especies vegetales productivas que dan cosechas más abundantes y nutritivas, más resistentes a diferentes plagas y en especies animales también se han obtenido mejoras y animales más productores de leche y con carnes más abundantes y ricas en nutrientes, lo que ha contribuido a disminuir el hambre en algunos sitios y promete seguir contribuyendo en este campo.

La clonación de seres humanos no se ha conseguido y tiene enormes dificultades técnicas. Quienes son partidarios de realizarla aducen dos finalidades, la primera obtener tejidos $\mathrm{u}$ órganos con fines terapéuticos, es la llamada clonación terapéutica, la otra finalidad es con fines reproductivos, obtener un ser igual al que donó en núcleo (clonación reproductiva).

El principal problema ético de este procedimiento en los seres humanos es el irrespeto por la vida humana por el número alto de embriones que se pierden en el intento y por convertir la procreación humana en un procedimiento de laboratorio. Los dos tipos de clonación de los que hemos hablado tienen serios problemas éticos, y la terapéutica además implica destruir los embriones para extraerles las células madre, es tener un ser humano y utilizarlo como cosa, para aliviar a otro.

\section{Las células madre y la medicina regenerativa.}

Este tema está íntimamente unido a la búsqueda de la inmortalidad o al menos de prolongar la duración de la vida humana. Algunas enfermedades se pueden tratar con transplantes: cambiar un órgano enfermo por otro sano, pero en un futuro próximo muchas enfermedades degenerativas como el Parkinson, la diabetes, se podrán tratar haciendo que el órgano o tejido enfermo se regenere y vuelva a funcionar adecuadamente. Las células madre son células pluripotentes, que pueden dar origen a diferentes tejidos y que puestas en un tejido enfermo pueden regenerarlo, por ejemplo, los pacientes que sufren de la enfermedad de Parkinson tienen un daño en algunos núcleos basales del cerebro que dejan de producir una sustancia llamada dopamina, con la ayuda de células madre colocadas en esos núcleos se puede lograr que vuelvan a producir la sustancia y mejoren los síntomas.

En la actualidad las fuentes de células madre (11) son básicamente tres: las células obtenidas de los embriones humanos, las células obtenidas de tejidos adultos y las del cordón umbilical $(12,13)$. Las primeras se obtienen de embriones humanos que se han creado por fecundación in vitro, las segundas están en nuestra sangre, en la piel, en la grasa, y las del cordón umbilical se recogen cuando un niño nace. Existió un debate en ańos pasados respecto a que tipo de células eran mejores para los efectos de la medicina regenerativa y en la actualidad hay una mayoría de científicos que afirman que son más seguras, más fáciles de obtener y de manejar e igualmente eficaces las células madre adultas, y además no tienen el problema ético que tiene el uso de células embrionarios dado que su obtención implica la destrucción del embrión humano $(14,15)$.

\section{Diagnóstico prenatal y eugenesia. Eugenesia} significa buen engendramiento, muchos pretenden tener una raza humana perfecta, deshacernos de todos los que están enfermos, de los imperfectos. La eugenesia ha sido un ideal de algunas personas desde prácticamente el comienzo de la humanidad. Se han usado diferentes mecanismos: esterilizar a quienes tienen posibilidad de engendrar personas enfermas, dejar morir a los que nacen deformes y débiles, exterminar millones de judíos por ser una raza que no merecía vivir. En la actualidad la eugenesia tiene un instrumento que 
es el diagnóstico prenatal en sus diversas formas (ecografía, amniocentesis, diagnóstico genético preimplantatorio). Hoy en día es asequible a mucha gente y se ha convertido en un poderoso método de eugenesia, un diagnóstico prenatal de mongolismo, o de una enfermedad cardíaca se ha convertido en causa de sentencia de muerte, de aborto. Hay una intolerancia total con la enfermedad, con quien no está sano y perfecto, "un primer problema de la eugenesia en todas sus clases es que es intrínsecamente eutanásica. En efecto, la selección se traduce en eliminación, sea en la fase prenatal, sea en el neonato o incluso más avanzada. Otro efecto es que crea un sistema de valoración social claramente anti igualitario, y ese valor, la igualdad, tiene un contenido político de primer orden" (16). La eugenesia actual es diferente a la antigua, en la antigua Grecia mataban a los niños que nacían deformes, Hitler mató niños y adultos, ahora matamos niños indefensos en el vientre materno porque son portadores de un gen que consideramos malo, cuando todos nosotros somos portadores de genes que tal vez otro pueda considerar indeseable. En París en el periodo 2001-2005 se dieron 499 casos de síndrome de Down; todos ellos confirmados con tecnología de citogenética, con la máxima eficiencia. La mayoría -cerca del 90\%-fueron eliminados. Se les aplicó la "TOFPA: Terminación del Embarazo por Anomalía Fetal” (17).

\section{Bioética un puente entre los científicos y los humanistas}

Los adelantos científicos han servido enormemente a la humanidad, pero también los hay que se han vuelto contra el mismo hombre. Esto ha sido manifestado por diferentes autores a lo largo de los últimos años, Potter temía por la deshumanización de la sociedad dada la esencia amoral del conocimiento científico, pensaba que la ciencia no es garantía de nada, porque a sus realizaciones le son ajenas las preocupaciones éticas. Potter decía "Existen dos culturas, que parece que no son capaces de comunicarse: la científica y la humanística. Si aceptamos que esta incomunicación es una de las razones que hacen dudar de la posibilidad de futuro de la humanidad, posiblemente construyendo un puente entre estas dos culturas construiremos un puente hacia el futuro..."(18). Ernesto Sábato también teme por lo que puedan hacer los científicos: "Este es el hombre moderno. Conoce las fuerzas que gobiernan el mundo, las tiene a su servicio, es el dios de la tierra: es el diablo. Su lema es: todo puede hacerse. Sus armas son el oro y la inteligencia. Su procedimiento es el cálculo"(19).

\section{El reto del cientificismo}

El cientificismo es la religión actual de muchas personas y de muchos científicos, lógicamente hay muchas y honrosas excepciones. Muchas personas, científicos o no, le rinden culto a los avances de la ciencia y tienen puesto en ellos su esperanza. Es cierto que la ciencia es una realidad actual y todos los días nos sorprende con avances fantásticos lo que obnubila la mente de algunos y los lleva a considerar que la ciencia es capaz de dar explicación de todas las realidades (20). La ciencia puede dar información de cómo funciona el cuerpo humano, pero no nos dice que es el hombre, nos muestra unas propiedades físicas o químicas de la vida, pero no nos dice que es la vida. Si fuéramos a señalar sus principales mandamientos de los cientificistas podríamos mencionar los siguientes:

- La ciencia es todo. La ciencia es una realidad sagrada e infalible.

- La ciencia nos salva. Debemos tener una seguridad absoluta en el progreso del hombre y su futura y total felicidad gracias a los avances de la ciencia. El futuro está en la ciencia.

- La ciencia es un dios al que hay que alabar y los científicos sus ministros.

- El avance de la ciencia puede pasar por encima de los seres humanos. No importa la vida sino la "calidad de vida". La investigación científica debe estar al margen de las consideraciones éticas (21).

- Los seres humanos son sólo un mico que tuvo suerte en la evolución. ¿¿Quién ha visto el alma, quien la ha podido tocar, cuánto pesa? "Yo soy un conglomerado de agua, calcio y moléculas orgánicas llamado Carl Sagan."

- Tener la ciencia es tener el poder. Todas las especulaciones de la ciencia son apropiados, 
cuando no esenciales, para la propia comprensión de todo el conocimiento humano incluida la religión.

La ciencia nos ha dado enormes beneficios, en el campo de la salud vemos como el promedio de vida que hace 50 años era de 30-40 años hoy está en 70 o más, fruto del control de un enorme número de enfermedades, en otros campos los avances son incontables y muy útiles, mencionemos solo el campo de las comunicaciones. Pero la ciencia no nos puede resolver todas nuestras incógnitas: ¿quienes somos, de donde venimos, cual es nuestro destino, que es el dolor? ¿Para que vivimos, por qué amamos, por qué luchamos, por qué nos sentimos llamados a hacer el bien? ¿Por qué nos preguntamos después de hacer algo si lo hicimos bien o no? La ética busca dar respuesta sobre el bien y el mal, pretende guiarnos en nuestras acciones y a lo largo de la historia de la humanidad se han dado diferentes propuestas sobre esto. Indudablemente el modelo bioético que se asuma tiene una íntima relación con la concepción de lo que es la persona que tengamos. La antropología y la ética van de la mano.

\section{Modelos bioéticos contemporáneos}

Siguiendo a Sgreccia(22) veamos los principales modelos bioéticos actuales

1. Modelo materialista. El materialismo considera que la persona es sólo un maquina que cuando está enferma hay que repararla, los biólogos y médicos materialistas no han visto el alma en su disecciones ni en sus cirugías. Si las personas son sólo cosas no tenemos que preocuparnos mucho por ellas, el respeto sobra. La vida - para ellos- es un paréntesis entre la nada y la nada.

2. Modelo socio-biologista. En este modelo la ética es algo descriptivo, es un fenómeno social y biológico. La sociedad en su evolución produce y cambia valores y normas, que son funcionales para su desarrollo, de la misma manera que hay una evolución biológica la sociedad debe cambiar y los valores morales evolucionan y cambian. El "deber ser" es producto de la evolución de la especie.

Entre naturaleza, ética y cultura hay relación íntima. Todo progreso está bien, la eugenesia, la clonación, la investigación con embriones humanos y su destrucción es algo correcto.
Da por sentado el evolucionismo y él lo que es el ser humano, su valor se reduce a lo que se piense de él en ese momento histórico (reduccionismo del hombre a un momento historicista y naturalista). El hombre es un mico que tuvo suerte en la evolución, a aprendido una serie de destrezas, pero en si tiene el mismo valor y merece el mismo respeto que un animal. Para ellos la biología puede desvelar por completo los misterios de la vida humana.

Peter Singer, filósofo australiano es un abanderado de los derechos de los animales, afirma que la diferencia entre un animal y el hombre es sólo de grado no de especie. A quienes hacen experimentación animal les pregunta si ¿están dispuestos a hacerlo en un niño con retardo mental?, afirma que un chimpancé puede tener una vida más rica y compleja que un niño discapacitado. Lidera en la actualidad el Proyecto Gran Simio que lucha por los derechos de los animales.

Para ellos toda ética y valor humano es algo relativo, los delitos del Gengis Kahn o de Hitler son malos solo para nosotros, por el momento cultural que vivimos, en su contexto histórico estuvieron bien.

Si bien es cierto que la cultura y las costumbres pueden evolucionar, pero el hombre sigue siendo hombre, diverso por naturaleza de cualquier otro ser vivo, con una inteligencia y una razón que le permiten conocer el bien y el mal. Puede que su cuerpo haya evolucionado, pero su naturaleza racional no. El bien y el mal no son conmutables entre si, ni falsas y verdaderas al mismo tiempo las leyes del ser, de la ciencia y de la moral. Si se niega que el bien y el mal son conceptos absolutos caemos en el relativismo, postura ética en que todo vale, lo que es malo para mi tengo que tolerarlo en usted porque para usted eso es bueno, es decir, al Mono Jojoy y a Granobles no se les puede reprochar nada dado que lo que ellos hacen para ellos está bien.

3. Modelo subjetivista o liberal-radical. Para estos pensadores la moral no se puede fundamentar ni en los hechos, ni en los valores objetivos o trascendentales, sino sólo es una "opción" autónoma del sujeto. Ellos parten de la imposibilidad de conocer los valores. Como lo indica el nombre del modelo la libertad es el supremo y último punto de referencia: es lícito lo que se acepta como libremente querido y 
que no lesiona la libertad ajena. Su compromiso es la liberalización de la sociedad. El único límite es el de la libertad ajena (no de todos, de la de él que es capaz de valerse de ella). Para ellos el juicio moral es subjetivo, la verdad ética no puede ser conocida. El subjetivismo no da cuenta a nadie de sus acciones, el crea sus propios valores.

Hay que decir que la libertad no puede ser absoluta, nuestra libertad llega hasta donde está la del otro. La libertad no es hacer lo que se quiere, es poder escoger entre dos cosas la mejor, y para poder escoger la mejor es necesario conocer lo que vamos a hacer. El investigador que después de estudiar las posibilidades y valorarlas adecuadamente escoge una está actuando más libremente que aquel que caprichosamente o sencillamente por comodidad escoge la más fácil. La libertad siempre debe ir unida a la responsabilidad, por esto a una persona irresponsable que hace mal uso de su libertad y comete un delito los jueces pueden privarlo de su libertad, porque no la sabe ejercer adecuadamente.

A estas personas subjetivistas se les dificulta tener una norma social, especialmente frente a quien, en aras del principio de autonomía, no acepta auto limitarse.

4. Modelo pragmático-utilitarista. Los pragmáticos niegan poder conocer una verdad universal, y por tanto una norma válido para todos en un plano moral. Su principal postulado es el máximo placer para el mayor número de personas. El bien es lo útil, lo práctico, la fácil. «La utilidad para mi» es el único criterio ético. El principio de acción es el cálculo de las consecuencias de las acciones con base en la relación costo/beneficio, costo/eficacia. Tiene relación con el Neoliberalismo de Stuart Mill y Bentham con su triple precepto: maximizar el placer, minimizar el dolor y ampliar la esfera de las libertades personales al mayor número de personas. Todo lo reducen a calidad de vida, para ellos no valen los enfermos, débiles, los improductivos, los dementes, estos son "desechables". Los utilitaristas no tienen amigos, siempre actúan por conveniencia. Ejemplo de cómo se manifiesta esto a nivel macro es ver como países que contaminan el medio ambiente no firma acuerdos para disminuir esa contaminación porque no quieren gastar dinero, permiten que se pierdan toneladas de alimentos mientras en el mundo hay mil millones de personas pasando hambre.

El utilitarismo es una civilización basada en producir y disfrutar; una civilización de las cosas y no de las personas; una civilización en la que las personas se usan como si fueran cosas. Dentro de este modelo es necesario mencionar el principialismo que pretende ser un marco normativo para la toma de decisiones éticas especialmente en el campo de la investigación biomédica y en la medicina, algunas veces investigadores de ciencias sociales aplican estos principios en su investigación (23).

El principialismo es muy usado en la bioética actual, especialmente en la anglosajona, se usa mucho para regular la investigación médica. En los orígenes del principialismo esta William David Ross un filósofo moral británico que defendió el intuicionismo y discutía que hubieran verdades ética objetivas. Publicó un libro titulado Derecho y lo bueno. Ross influyo en Tom Beauchamps y James Childress que en 1976 publicaron el libro Principles of biomedical ethics. Es el libro que tiene más importancia histórica en el principialismo. Hablaba inicialmente de 3 principios: beneficencia, justicia y autonomía, luego añadió el de no maleficencia y explicó que se debían aplicar no solo a la investigación sino a toda práctica médica.

a.) El principio de beneficencia-no maleficencia (en el caso de la medicina) manda hacerle mayor bien posible y se podría puntualizar en los siguientes puntos: buscar hacer el bien, evitar el mal; la investigación con seres humanos debe ser realizada por personas calificadas; si se puede es preferible hacerla en animales o tejidos antes que en humanos; se debe proteger al sujeto de daños psicológicos, darle garantía de que no va a haber explotación y de que no se va a usar la información que se obtenga en contra ellos.

b.) El principio de respeto a la autonomía del paciente. El paciente debe ser quien toma las decisiones. Los elementos de este principio los siguientes: el derecho a la autodeterminación en un tratamiento; el derecho a decidir voluntariamente si se participa en un estudio sin temor a represalias; el derecho a rehusar dar una información o a dar por terminada la participación; el derecho a no recibir coerción de 
ningún tipo; el derecho a tener un conocimiento completo de la información disponible. De aquí nace algo muy conocido y que se aplica en la práctica clínica diaria que es el consentimiento informado.

c.) El principio de justicia señala tratar de manera justa y equitativa a los sujetos de la investigación. Se pueden señalar algunos puntos: el derecho al trato justo y equitativo, antes, durante y después de su participación en una investigación; la selección justa y no discriminatoria de los sujetos, de manera que los riesgos y beneficios se compartan equitativamente; el trato sin prejuicios de quienes se rehúsan a participar o que abandonan el estudio; el trato respetuosos y amable todo el tiempo; que se mantenga la más estricta confidencialidad.

Los principios buscan una referencia práctica y conceptual, pero a pesar de lo señalado no aclaran que se debe entender por cada uno de ellos, en un momento determinado la beneficencia para un investigar es continuar la investigación y para otro es suspenderla, puede ocurrir que lo que una persona considera un beneficio para otro sea causar un daño (si una mujer solicita la eutanasia porque esta sufriendo mucho - para ella sería un beneficio-, pero el médico conceptúa que causar la muerte es un daño y desde ningún punto de vista es aplicar la beneficencia). En este mismo ejemplo también choca la autonomía de la paciente con la autonomía del médico. Por esta falta de claridad y de conflicto entre ellos los principios norteamericanos han perdido protagonismo, de hecho en el mundo europeo no anglosajón no han tenido mayor relevancia. Los principios llevan a una actitud de obediencia pasiva, más que un comportamiento activo de compromiso moral. Los principios entre si no están coherentemente vinculados mediante una antropología personalista fundamental.

El principialismo tiene el inconveniente que los principios admiten excepciones y que les falta una antropología y una metafísica de base. Es una ética de convivencia pacífica. Los autores del principialismo tenían una serie de problemas que resolver, deseaban avanzar en la práctica de la fecundación in vitro, la investigación con embriones humanos, los transplantes y diseñaron unos principios que se los permitía, usaron un método inductivo para crearlos, no un método deductivo para conocerlos.
5.) Modelo personalista. El personalismo permite fundar los valores y normas de manera objetiva (24). El hombre es persona porque es el único ser en el que la vida es capaz de reflexionar sobre sí mismo, de auto determinarse. Es el único viviente capaz de captar y descubrir el sentido de las cosas y de dar sentido a sus expresiones y a su lenguaje consiente.

El personalismo considera que el ser humano es un ser personal, único e irrepetible, inviolable y trascendente investido de una dignidad propia que lo hace merecedor de todo el respeto. Aunque tengamos una similitud en los genes con los animales y tengamos procesos bioquímicos iguales a ellos somos fundamentalmente distintos. No es la genética la que nos señala las diferencias, es la razón, nos damos cuenta de que podemos pensar, elaborar pensamientos, abstraer conceptos: conocemos a nuestros alumnos y podemos elaborar el concepto alumno que se aplica a ellos y a todos, son conceptos universales; el ser humano tiene un proyecto de vida, proyecta su futuro; ha creado el lenguaje y se puede comunicar con los demás; crea entes abstractos como las matemáticas; puede ver en las demás personas seres iguales a él; y se pregunta si lo que está haciendo está bien o no. Se proyecta en el futuro y recuerda el pasado, tiene capacidad de decidir, se da cuenta que posee libertad propia, distingue entre el bien y el mal, es capaz de darse a los demás.

La persona ve en los demás personas iguales él y de allí nace la obligación de no hacer a los demás lo que no queremos que nos hagan a nosotros: el respeto que es el primer principio de la ética. El respeto de esa dignidad concierne a todos los seres humanos, porque cada uno lleva inscrito en sí mismo, de manera indeleble, su propia dignidad y valor.

Sólo por el hecho de existir, cada hombre tiene que ser plenamente respetado. Hay que excluir la introducción de criterios de discriminación de la dignidad humana basados en el desarrollo biológico, psíquico, cultural o en el estado de salud del individuo. La dignidad pertenece de igual modo a cada ser humano individual y no depende del proyecto familiar, la condición social, la formación cultural o el estado de desarrollo físico o la salud. La persona tiene un valor intrínseco, inviolable y trascendental, a esto se llama dignidad humana. Dice Melendo que 
"aún en el caso que la sociedad por consenso decidiera que no hay que respetar la dignidad esta habría que reconocerla en cada persona". A cada ser humano, desde la concepción hasta la muerte natural se le debe reconocer la dignidad de persona. Frente a la dignidad humana ha de surgir el respeto incondicional.

La historia de la humanidad manifiesta un progreso real en la comprensión y el reconocimiento del valor y la dignidad de cada persona, fundamento de los derechos humanos y de los imperativos éticos con los que se ha intentado y se intenta construir la sociedad.

El respeto por la vida es un principio fundamental del personalismo, admitiendo que no es un valor absoluto pero sí el más alto. El derecho a la vida es el primer derecho, si no estamos vivos no podemos hablar del derecho a la salud, a la educación, etc. Pero hay que reconocer que si la vida fuera un valor absoluto no se podría prestar el servicio militar y los creyentes no podrían dar la vida por su fe.

La vida realmente es un misterio revestido de dignidad. En estos tiempos, -dice Leon Kass- defender la dignidad de la vida humana no es cosa de broma. Entre las amenazas actuales a nuestra condición humana, las más profundas vienen del ámbito más inesperado: nuestras maravillosas y muy humanas ciencia y técnica biomédicas. El poder que nos otorgan para modificar el funcionamiento de nuestros cuerpos y de nuestras mentes se está empleando ya para fines que exceden la terapia, y quizá pronto se podrá usar para transformar la misma naturaleza humana (25).

\section{¿Qué papel juega la bioética? ¿̇ué hacer frente a los avances científicos?}

La bioética tiene hoy en día un papel preponderante en la sociedad, es una disciplina que debe enseńarse en los colegios y universidades, que debe proponerse ayudar a que la sociedad adquiera conciencia de los riesgos que se ciernen sobre la sociedad si los adelantos biotecnológicos no se utilizan responsablemente. "¿Qué queremos proteger de los futuros avances de la biotecnología? -se pregunta Fukuyama, y responde-: La respuesta es que queremos proteger el conjunto integro de nuestras naturalezas, complejas y evolucionadas, contra cualquier intento de auto modificación. No deseamos que se alteren la unidad o la continuidad de la naturaleza humana y, por lo tanto, los derechos que se basan en ella"(26).

Indudablemente los avances científicos continúan, su crecimiento es grande y rápido y nadie lo va a detener, pero si se pueden y deben orientar. Es necesario tener una adecuada valoración de los adelantos científicos frente al ser humano, es necesaria una escala de valores correcta. La ciencia debe estar al servicio de la persona y no la persona al servicio de la ciencia o del más fuerte.

La bioética juega un papel importante en la actualidad, me refiero a la bioética respetuosa de la persona humana, que sabe compaginar los desarrollos tecnológicos y los avances científicos con el respeto por la vida. Todos ańoramos una cultura de respeto de unos por otros, en la que prime la persona sobre los intereses personales económicos o de dominio. La ciencia, el conocimiento es poder, pero no debe ser usado como instrumento de los fuertes contra los débiles. La ciencia no puede ser neutra porque sus descubrimientos se aplican de alguna forma y en esa aplicación se puede estar haciendo algo bueno o algo mal. La energía nuclear no es neutra, será buena si se aplica para curar el cáncer por ejemplo y será mala si se utiliza en la guerra.

Fukuyama escribe "La ciencia no puede, por si misma, establecer los fines a cuya consecución se consagra. Puede descubrir vacunas y curas para las enfermedades, pero también puede crear agentes infecciosos; puede revelar la física de los semiconductores, pero también la física de la bomba de hidrogeno. A la ciencia, en cuanto ciencia, no le importa si la información se obtiene de acuerdo con una normas que protejan escrupulosamente los intereses de los humanos objeto del estudio. La información, al fin y al cabo, es información, y la mejor información a menudo puede conseguirse quebrantando las normas o prescindiendo de ellas por completo. Muchos médicos nazis que inyectaron agentes infecciosos a las víctimas de los campos de concentración, o que las congelaron o abrasaron hasta matarlas, eran de hecho científicos legítimos que recabaron información real que potencialmente podía utilizarse para el bien" (27).

La situación es única, es delicada, ¿qué va a pasar?, no lo sabemos, pero tenemos que hacer algo, 
no podemos quedarnos sólo como observadores pasivos o lamentándonos si ocurre algo grave. La bioética debe trabajar en el campo de la educación, hay que volver a la enseñanza de la ética aristotélica tomista, debe ser una ética fundada en el respeto por los demás, un respeto en la naturaleza de las cosas que es volver a estudiar la ley natural. La filosofía tomista esta desprestigiada en algunos ambientes no porque sea algo ridículo o pasado de moda, sino porque no se ha sabido exponer con claridad, quienes han tenido la responsabilidad de enseñarla lo han hecho muchas veces en base a argumentos de autoridad, sin argumentos razonable, sin análisis, sin profundizar. La argumentación con la que cuenta es muy sólida, y por eso ha pervivido con el paso de los siglos.

Los modelos bioéticos pragmáticos o liberales son modelos a primera vista atrayentes, son prácticos, dan resultados, no requieren mayor análisis ni raciocinio, son rápidos y fáciles, no hay que estudiar mayormente para ponerlos en práctica, son extremadamente egoístas, yo decido lo que está bien y lo que está mal, el único criterio es la conveniencia y al final la justificación si hay que dar alguna es "eso todo el mundo lo hace", o "yo no le veo nada malo".

Interviniendo como invitado a una reunión de dos academias, la Academia de Ciencias de Paris y la Academia Pontificia para la Ciencia Benedicto XVI decía: "El ser humano tiene una capacidad específica: discernir lo bueno y el bien». «En nuestra época, cuando el desarrollo de las ciencias atrae y seduce por las posibilidades ofrecidas, es más importante que nunca educar las conciencias de nuestros contemporáneos para que la ciencia no se transforme en criterio del bien, y el hombre sea respetado como centro de la creación y no se convierta en objeto de manipulaciones ideológicas, de decisiones arbitrarias, ni tampoco de abuso de los más fuertes sobre los más débiles»(28), concluyó el Benedicto XVI.

Fukuyama (29), Testart (30) y otros son partidarios de crear comités que sean los encargados de regular las nuevas tecnología y su aplicación (Fukuyama también considera importante la autorregulación, Testart posteriormente no consideró que fuera la solución definitiva), pero estos comités no son garantía de nada. En la Comisión Nacional de
Bioética del presidente de los Estados Unidos han tomado asiento personas muy preparadas y con criterios éticos respetuosos de la persona humana como han sido Leon Kass, Edmund Pellegrino, ahora recientemente el presidente Obama ha reestructurado la Comisión para poner allí personas más proclives a su pensamiento y a permitir el desarrollo de tecnologías que no respetan el embrión humano. Estas comisiones no parecen ser la solución, con frecuencia adquieren un tinte ideológico y pierden objetividad, pueden ser manejadas por diferentes intereses. La mejor solución está en la educación, la sociedad actual, ya lo hemos dicho, tiene intereses muy variados, esta deslumbrada por los avances científicos y no se detiene a pensar y considerar valores como el respeto a la persona, a la dignidad de los demás, se valoran excesivamente los derechos propios y no los deberes. En la medida que los científicos sean personas integras, con una formación humanística y ética, los abusos y atropellos que hemos visto en otros momentos de la historia disminuirán o desaparecerán.

La definición primera que se hizo de bioética es "estudio sistemático de la conducta humana en el ámbito de las ciencias de la vida y del cuidado de la salud, analizados a la luz de los valores y principios morales (31)." Presupone una formación en principios morales, lo que proponemos es justamente que se forme en principios respetuosos de la persona, de la dignidad y del respeto a las nuevas generaciones, a los educadores, a los científicos, a los dirigentes y a los políticos, la responsabilidad es grande y no podemos soslayarla. Otra definición la hace Francisco J. León C. y dice que "Llamamos bioética a la búsqueda del conjunto de exigencias del respeto y de la promoción de la vida humana y de la persona en el sector bio-médico" (32), y señalo la importancia de promover la dignidad de la vida humana en todos los ámbitos.

Si la universidad renuncia a su función educativa, corre el riesgo de formar bárbaros científicamente competentes, que constituye el tipo más peligroso de ser humano que existe en la actualidad. La ciencia no lo es todo, un científico puede conocer el material de que está construido un edificio, la cantidad de cemento, la profundidad de los cimientos, el peso total, pero si ese edificio es una catedral puede ocurrir 
que no sabe que significa catedral, de igual manera el análisis químico del agua de un rio jamás nos informará de su recorrido (33). Mencionaba antes una frase de Carl Sagan "Yo soy un conglomerado de agua, calcio y moléculas orgánicas llamado Carl Sagan" y no podemos negar que el cuerpo humano es agua, calcio y otros elementos, pero somos mucho más que eso, somos seres con afectos, con ilusiones, intereses, inteligentes, que apreciamos el arte y podemos comprender lo que significa una catedral. La universidad debe formar fundamentalmente la persona, ayudarla a crecer, no puede contentarse con formar técnicos, al fin y al cabo para eso tal vez no es necesario ir a la universidad. En la cultura helénica no tenían los conocimientos y desarrollos que hoy tenemos, pero tenían la posibilidad de pensar, de observar, de analizar y así nos dejaron esos pensadores conceptos fundamentales y que persisten absolutamente sólidos 25 siglos después.

La Bioética no puede ser un elenco de opiniones. Debe sugerir valores de referencia y lineamientos operativos cuando se tiene que tomar una decisión. Debe comprometerse en proporcionar respuestas objetivas sobre criterios racionalmente válidos. No puede faltar la confrontación, pero en un marco de discusión crítica y de orientación normativa, sólo una ética ontológica puede ser normativa.

Esta batalla por la educación hay que darla de manera especial con todo el personal que trabaja en las ciencias de la vida: la biología, la medicina, la genética (34). El mensaje que hay que transmitirles es que no todo lo que es posible técnicamente se puede realizar, que los avances necesariamente deben tener un límite, que el principio de no maleficencia sigue vigente. Además es tanto lo que desconocemos de las ciencias que el principio de prudencia tiene en esta época actual una vigencia extraordinaria. Por último la campaña hay que darla en la formación de nuestros gobernantes, realmente en todo el mundo hay una crisis de valores grande y especialmente entre los que nos gobiernan que por querer estar a la moda están proponiendo leyes para legalizar la clonación, la investigación con embriones, etc.

Los bioéticos algunas veces no han estado a la altura de las circunstancias, se han dejado halagar por los científicos descuidando su labor orientadora, lo denuncia Francis Fukuyama, economista y consultor universitario, libre de toda sospecha ideológica cuando dice «La comunidad de bioéticos que ha surgido paralelamente a la industria biotecnológica es, en muchos aspectos, un arma de doble filo. Por un lado, ha cumplido una función extremadamente útil al plantear dudas y cuestiones sobre la prudencia y la moralidad de ciertas innovaciones tecnológicas. Por otro, muchos bioéticos se han convertido en poco más que justificadores sofisticados (y sofistas) de todo cuanto la comunidad científica desee hacer, con conocimiento suficiente de teología católica y de metafísica kantiana para rebatir los argumentos de cualquiera que, partiendo de esas tradiciones, mantenga una oposición más enérgica» (35).

Una sociedad sin valores no puede persistir, es necesario formar a los jóvenes, a los médicos, a los científicos, a los ciudadanos en el respeto y la responsabilidad. No todo lo que es posible hacer se puede hacer, los adelantos tecnológicos necesariamente tienen que tener un límite, la ciencia no puede volverse contra el hombre, es necesario que el hombre use la ciencia y enseñe a usarla con responsabilidad, los daños que se pueden ocasionar son irreparables. Esa responsabilidad debe llevar a los científicos y tecnólogos a moderar sus impulsos y su pasión por saber y por hacer: figurar, sobresalir, ser reconocido por la sociedad como un científico está bien, pero ser un científico tristemente célebre como un Oppenheimer, un Nobel por no mencionar a Mengele, debe ser algo que necesariamente deja un mal sabor.

El cientificismo se enfoca principalmente en la ciencia y desconoce realidades supremamente importantes como la persona y su dignidad, el ser humano necesariamente debe estar por encima de la ciencia. Se debe buscar que la sociedad este regida por hombres sabios, responsables, capaces de comprender el ser humano en todos sus aspectos, con una visión trascendente, expertos en humanidad como la Iglesia. "Así se reafirma la primacía del hombre sobre las cosas, las cuales están destinadas a él y confiadas a su responsabilidad, mientras que por ningún motivo el hombre puede ser sometido a sus semejantes y reducido al rango de cosa" (36). 


\section{Conclusiones}

Frente a los adelantos científicos que no se detienen y que seguramente seguirán creciendo de una manera rápida es necesario formar a los jóvenes universitario, educadores, padres de familia y a la sociedad en general en principios éticos respetuosos de la persona humana, sabiendo mostrar el valor de los adelantos científicos pero también el valor de la persona y el respeto que merece, seńalando que todos esos adelantos deben respetar la dignidad humana, deben estar al servicio de la humanidad sin convertirse en un fin en si mismo ni en algo que termine devorando a los seres humanos.

Los atropellos contra la persona han ocurrido en diferentes momentos históricos, han aparecido diferentes normativas internacionales conocidas, se han propuesto diferentes tipos de comités para vigilar y controlar el desarrollo de la ciencia y la tecnología, pero lo que realmente va a ser eficaz es formar a la sociedad en los principios bioéticos que garanticen el respeto y la armonía e igualdad de todos. Los estudios del genoma y el diagnóstico prenatal tienen graves peligros de ser discriminatorios.

La ética personalista es la que mejor considera y valora a la persona, tiene diferentes exponentes, todos muy respetuosos y que se complementan entre si en la filosofía de la persona.

\section{Referencias}

1. Potter, Van Rensselaer. Bioethics, the science of survival. Biology and Medicine: 14 (1), 127-153. 1970.

2. Kottow, M. Introducción a la bioética. Mediterráneo,, 2005, p. 8

3. Lara Roche, C. Manual de bioética. Defensa y promoción de la persona. Ed. San Pablo, Guatemala, 2007, p.17

4. Moyer, T., O'Kane, D., Baudhuin, L. y cols. Warfarin Sensitivity Genotyping: A Rewiew of the Literature and Summary of Patient Experiece. Mayo Clinic Proceedings, December 2009 vol. 84 no. 12 1079-1094

5. Garcia-Foncillas, J. y Bandrés, E. Medicina individualizada: farmacogenómica en cáncer. Humanitas, on line, n. 33, 2008

6. Marianne Dion-Labrie, M., Fortin, M.C., Hébert, M.J. y Doucet, H. Reflexiones éticas sobre la medicina personalizada: ¿la alianza entre ciencia y la medicina, realizada por fin? Revista Colombiana de Bioética. Vol. 3 No 2 - Diciembre 2008, p. 57-81

7. Rovira Viñas, A. Reflexiones sobre el derecho a la intimidad en relación con la informática, la medicina y los medios de comunicación. Revista de Estudios Políticos (Nueva Época) Núm. 77. Julio-Septiembre 1992, P.259

8. Garrido Sanjuán, J.A. Indiscreción y derecho a la intimidad en el sistema sanitario Med Clin (Barc). 2000; 114:358-9.

9. Kakuk, P. Genetic information in age of genohype. Med Health Care Philos. 2006: 9(3): 325-37
10. Kass, R., Verhoef, S., Wesseling, J. y cols. Prophylactic mastectomy in BRCA1 and BRCA2 mutation carriers: very low risk for subsequent breast cancer. Ann Surg. 2010, Mar: 251(3): 488-92

11. Flores-Figueroa E, Montesinos J.J. y Mayani, H. Células troncales mesenquimales. Rev Invest Clin 2006; 58 (5): 498-511

12. Frey M.A., Guess C. y cols. Umbilical cord stem cell transplantation. Semin Oncol Nurs, 2009, vol.25 n.2: 115-9

13. Ruhil, S., Kumar, V. y col. Umbilical cord stem cell: an overview. Curr Pharm Biotechnol. 2009, vol. 10 n. 3:327-34

14. Flores-Figueroa E, Montesinos JJ. y Mayani, H. Células troncales mesenquimales. Rev Invest Clin 2006; 58 (5): 498-511

15. Weissman, I. Stem cell research. Paths to cancer therapies and regenerative medicine. JAMA, 2005, 294: 1359 -1366

16. Serrano Ruiz-Calderón, J.M. Retos jurídicos de la bioética. Ediciones Internacionales Universitarias, Madrid, 2005, p. 25

17. Boyd P, DeVigan C, Khoshnood B, Loane M, Garne E, Dolk H, and the EUROCAT working group. Survey of prenatal screening policies in Europe for structural malformations and chromosome anomalies, and their impact on detection and termination rates for neural tube defects and Down's syndrome. BJOG 2008;115:689-696.

18. Potter, Van Rensselaer. "Bioethics, Bridge to the future". Englehood Cliffs (ed), N.J.: Prentice Hall, 1971.

19. Sábato, Ernesto. Hombres y engranajes. Alianza editorial, 1973

20. Alonso, C.J. La agonía del cientificismo. Una aproximación a la filosofía de la ciencia. Eunsa, Pamplona, 1999, p. 65

21. Kottow, M. Introducción a la bioética. Mediterráneo,, 2005, p. 145

22. Sgreccia, Elio. Manual de Bioética. I. Fundamentos y ética médica. BAC, 2009, cap. II

23. Cfr. Alcaraz, Gloria y Correa, Adriana. La ética en la investigación: el caso con los tule (kunas) de Urabá, Colombia. Biomédica, vol 26, n. 1, 2006

24. Sgreccia, Elio. Manual de Bioética. Fundamentos y ética médica. BAC, 2009, cap. II

25. Leon R. Kass, doctor en Medicina y en Bioquímica, miembro del American Enterprise Institute, presidió (2002-2005) el President's Council on Bioethics, órgano asesor del presidente de Estados Unidos. Es autor de varios libros, entre ellos Life, Liberty and the Defense of Dignity: The Challenge for Bioethics (ver Aceprensa 106/03) y El alma hambrienta (ver Aceprensa 85/05). Este artículo es una traducción parcial del siguiente original: "Keeping Life Human: Science, Religion, and the Soul" by Leon R. Kass, M.D. Copyright (C) AEI, Washington, D.C., 2007. All rights reserved.

26. Fukuyama, Francis. El fin del hombre. Consecuencias de la revolución biotecnológica, Ediciones B, Barcelona, 2002, p. 277

27. Ibid. p 295-296

28. http://www.scriptor.org/2008/01/ciencia-y-conci.html 10 enero 2010

29. Fukuyama, Francis. El fin del hombre. Consecuencias de la revolución biotecnológica, Ediciones B, Barcelona, 2002, p. 293

30. Testart, J. Citado en: Monge, Fernando. Persona humana y procreación artificial. Libros MC, Madrid, 1988, p.95

31. Reich W.T. Encyclopedia of Bioethics, Nueva York 1978, I, p. XIX.

32. León C. F.J. Bioética razonada y razonable. Fundación Interamericana Ciencia y vida, Santiago de Chile, 2009, p. 18

33. Testart, J. y Godin, C. El racismo del gen. Biología, medicina y bioética bajo la férula liberal. Fondo Cultura Económica, México, 2001, p. 34

34. Ibid. p. 69

35. Fukuyama, Francis. El fin del hombre. Consecuencias de la revolución biotecnológica, EdicionesB, Barcelona, 2002, p. 324

36. Juan Pablo II. El valor inviolable de la vida humana. Carta encíclica "Evangelium vitae", BAC, Madrid, 1995, n. 34 